\title{
Suma qamaña $=$ convivir bien. ¿Cómo medirlo?
}

Xavier Albó

Centro de Investigación y Promoción del Campesinado (CIPCA)

\begin{abstract}
In the Political Constitution of the State, in force in Bolivia since 2009, the concept of "living well" is reiterated already in its Preamble and in its Title I by pointing out the great "ethical-moral principles of plural society" (art. 8). We also find it again in other subjects such as education (art. 80) and economics (art. 306, 313). What is behind such a concept? I will explore it in a gradual and increasingly expansive manner, first in purely linguistic terms and then in a broader scope, as the logic common to many indigenous and native peoples, as opposed to that of dominant societies and powers. In the end I will outline some strategies to translate this concept into more measurable indicators.
\end{abstract}

\section{Keywords}

Development, Living well, Mother Earth, Political Constitution of the State, Suma qamaña

\section{Resumen}

En la Constitución Política del Estado, vigente en Bolivia desde 2009, se reitera el concepto de "vivir bien" ya en su Preámbulo y en su Título I al señalar los grandes "principios ético-morales de la sociedad plural" (art. 8). Lo 
encontramos de nuevo también en otros temas como el educativo (art. 80) y el económico (art. 306, 313). ¿Qué está detrás de tal concepto? Lo exploraré de una manera gradual y cada vez más expansiva, primero en términos puramente lingüísticos y después en un ámbito más amplio, como la lógica común a muchos pueblos indígenas y originarios, contrapuesta a la de las sociedades y poderes dominantes. Al final esbozaré algunas pistas para poder plasmar este concepto en indicadores más medibles.

\section{Palabras claves}

Constitución Política del Estado, Desarrollo, Madre Tierra, Suma qamaña, Vivir Bien

Este trabajo fue originalmente publicado en un volume titulado Vivir bien: ¿Paradigma no capitalista? (2011). ${ }^{1}$ Pasados los años y habiendo caído Evo en Bolivia, como habiéndose manifestado cambios en el contexto global, lo que aquí se dice sigue siendo válido, y en cierta forma todavía más urgente. El vivir bien sigue siendo una oportunidad desatendida.

\section{La base lingüística y cultural aymara}

A veces las traducciones son traicioneras: traduttore traditore, dicen los italianos. Algo de ello ocurre con la expresión "vivir bien" si no se contextualiza en la lengua y cultura dentro de la que fue acuñada la fórmula aymara original suma qamaña, explícitamente mencionada en el artículo 8. Repasemos primero, pues, su sentido originario tanto en la lengua como en la cultura aymara. ${ }^{2}$ Será bueno entenderlo en su plenitud, para aplicarlo después correctamente. Analicemos y gocemos ante todo estas dos palabras:

\section{Qamaña}

Qamaña es "habitar, vivir [en determinado lugar o medio], morar, radicar" (to dwell, en inglés); y qamasiña es "vivir con alguien". Qamaña es también el nombre que se da al lugar abrigado y protegido de los vientos, construido con un semicírculo de piedras para que, desde allí, los pastores

\footnotetext{
${ }^{1}$ La version que ahora se publica es la misma, con mínimas actualizaciones editoriales.

2 Esta parte más lingüística está basada sobre todo en Félix Layme (2004), con quien he hecho además varias consultas personales.
} 
cuiden a sus rebaños mientras descansan. Es decir, desde sus diversos ángulos, qamaña es vivir, morar, descansar, cobijarse y cuidar a otros. En un segundo uso, insinúa también la convivencia con la naturaleza, con la Madre Tierra o Pacha Mama, aunque sin explicitarlo. Como nos enseñan los lingüistas, la raíz conceptual es qama-, a la que se van añadiendo diversos sufijos para agregarle nuevos matices, como por ejemplo -ña, que lo verbaliza.

Esto nos ayudará, por tanto, a ver algunos otros términos directamente asociados:

Qama-wi (con el localizador -wi) es "morada", pero qamäwi (nominalizador de la acción verbal) es, de una forma muy significativa, la "reunión de personas que acostumbran juntarse para conversar o pasar agradablemente el tiempo". Nadie llega a ser plenamente "persona" (jaqi) si no llega a formar pareja: la unidad mínima de convivencia que, además, es fuente de nueva vida. Por eso casarse se dice jaqichasiña: "hacerse persona", y estas parejas -que ya son familia-constituyen la base de toda la organización comunal. El concepto aymara de chacha-warmi resalta además que esta convivencia tiene algo de diferencia y complementariedad entre los que aprenden a convivir bien.

Qamasa, del gerundio "viviendo, conviviendo", es "el carácter, el modo de ser" y también "el valor, la audacia, el ánimo, el coraje". Se dice también que tal o cual lugar, incluso el sol, una wak'a o un cerro sagrado, tienen mucho qamasa. En ese sentido, y el más genérico, es un lugar de mucha energía y se hacen gestos y rituales para llenarse de esa energía. Qamasa es, por tanto, la "energía y fuerza vital para vivir y compartir con otros". Esta es quizás la relación más explícita entre la raíz qama-, como algo que está de manera muy fuerte y viva en la Pacha Mama, y nosotros que la habitamos y hacemos de ella nuestra morada.

La manera más común en aymara para decir que alguien es "rico" es Qami- ri. Actualmente, para hablar de gente rica, burguesa, prepotente, etc., muchos -aymaras o no- suelen recurrir a ese término en plural: qamirinaka. Pero, a la luz de lo anterior, no resulta tan claro que este sea el sentido original, aunque aparezca ya en los primeros diccionarios. La connotación más profunda no sería la de un rico que vive de una manera lujosa y prepotente a costa de los otros, sino más bien del que tiene en abundancia para poder compartir y celebrar con los demás.

Esto se nos acaba de aclarar al contrastar la manera de expresar regularmente que alguien es "pobre"; es decir, lo contrario de "rico". La palabra que tanto quechuas como aymaras prefieren siempre para decir pobre, 
mendigo, es waxcha (o waqcha, en quechua) que, en rigor, significa "huérfano, abandonado". Es decir, lo que se subraya ante todo es la falta de seguridad y del calor de la convivencia en su vida, más que la carencia de bienes materiales. En mi experiencia personal, a mi casa de Qurpa, Jesús de Machaqa (La Paz), acudía con frecuencia un célebre anciano pidiendo algo $y$, pese a sus muchos años, decía: "es que soy huerfanito". En Europa sorprendería que un anciano apelara a sus padres muertos muchísimo tiempo atrás. Pero en ese contexto aymara resulta más bien iluminador sobre qué hace a alguien rico o pobre: la capacidad de vivir acogido y compartiendo con los demás.

Todo este abanico de sentidos de qamaña, con una mayor referencia a la convivencia social y también ecológica, es más rico que los de jaka-ña, que es también "vivir" y "vida", pero sólo en el sentido de estar vivo en contraposición a estar muerto y a muerte (to live, en inglés). Por eso, cuando en el mundo andino y en tantos otros pueblos indígenas originarios, se afirma que las suyas son culturas para la vida, no se refieren sólo al hecho físico de vivir sino también a todo ese conjunto de relaciones sociales con un ambiente de acogida. Por eso se habla también de "cuidar" y "criar" la vida, como algo que hacemos juntos, en familia; connota además toda la manera en que cuidamos y protegemos nuestros cultivos y el medio ambiente.

En el más antiguo y clásico diccionario aymara de Bertonio (1612) se usa jakaña para los sentidos más simples de "vivir". Pero para "vivir en paz" y "vivir a gusto" recurre a qamaña: muxsaki qamaña "vivir no más dulcemente".

\section{Suma Qamaña}

Dos diccionarios recientes (De Lucca 1987, Layme 1994) describen suma como "bonito, hermoso, agradable, bueno, amable"; pero también "precioso, excelente, acabado, perfecto". Tiene, por tanto, un sentido de plenitud que no se le da en castellano. Y suma jaqi es "buena gente, bondadoso, generoso, que tiene buena voluntad a otro".

¿Por qué no quieren hablar tanto de vivir mejor? En su concepción, los pueblos originarios (al menos los andinos) no lo ven necesario precisamente porque suma (o sumaq en quechua) ya puede incluir en sí mismo "el mayor grado posible". Por otra parte, los aymaras que han reflexionado más sobre esta cuestión se resisten a decir "mejor" porque este término se entiende muchas veces como que un individuo o grupo vive y está mejor que otros y a costa de los otros. Suma qamasiña es [con]vivir bien, no unos mejor que otros ni a costa de otros. 
Eso último es lo que hace q'ara a alguien; más que el color de la piel (pues en realidad q'ara significa desnudo, pelado), es el que carece de algo fundamental. Equivale a "incivilizado", por no cumplir la regla y objetivo fundamental de la convivencia. Actualmente, muchos interpretan este término en un sentido racial; pero tal sentido sería sólo figurado, pues se aplica también a aymaras que ya no se comportan bajo las normas básicas de la convivencia. A partir de preguntas acerca del por qué a los muy ricos se les sigue llamando q'ara, cuando en realidad no les falta nada, la respuesta ha sido: "es que no tienen nada suyo, fruto de su trabajo".

En esta línea, lo contrario de suma qamasiña, "convivir con bondad y generosidad", sería q'araru tukuña, hacerse desnudo, incivilizado, por no tener algo fundamental. Obviamente, si hay formas de convivir que son buenas y generosas, también puede haber esas otras que no lo son, y en este caso el ideal es reforzar las primeras.

Por tanto, al decir sólo "bien" -en este sentido de suma(q) y en el contexto de qamaña- ya se connota que todo el conjunto social debe ser del todo bueno. No serviría para indicar simplemente que algunos están mucho mejor que los demás. Si mejoramos tiene que ser, en lo posible, todos a la vez para estrechar los lazos de convivencia.

Dentro de la cosmovisión aymara y andina, hay que resaltar -como ya hemos insinuado- que esa buena convivencia no se concibe que sea sólo entre personas o humanos. Abarca también a todo el contorno, los animales, las plantas y la Pacha Mama o Madre Tierra. Cuando se brinda entre amigos, por ejemplo, nunca se olvida compartir el traguito también con la Madre Tierra y con los achachilas o cerros-antepasados protectores de toda la comunidad.

Un documento preparatorio, distribuido por el Ministerio de Planificación del Desarrollo de Bolivia para un Seminario Internacional sobre el Vivir Bien (La Paz, 3-5 de noviembre 2009), propuso la siguiente glosa de este concepto:

El Vivir Bien implica el acceso y disfrute de los bienes materiales en armonía con la naturaleza y las personas. Es la dimensión humana de la realización afectiva y espiritual. Las personas no viven aisladas sino en familia y en un entorno social y de la naturaleza. No se puede Vivir Bien si los demás viven mal o si se daña la naturaleza.

En el contexto aymara y andino, se podría haber precisado que no se trata sólo de los bienes "materiales" sino también de los espirituales, como 
son todos los intercambios de reciprocidad, los compadrazgos y las celebraciones, que van siempre tan cargados de afecto y cariño. Además, se podría añadir que las familias aymaras tampoco viven aisladas sino en una red de intercambio intenso con el resto de su comunidad y ayllu. Se debe dar, asimismo, un carácter más personalizado y afectivo a la Naturaleza, con la que se entablan relaciones de reciprocidad, viéndola y sintiéndola como Pacha Mama, sin entrar a más detalles sobre ese complejo universo que relaciona la naturaleza, la producción, el mundo espiritual y el social.

Como nos enfatizó Dominique Temple en el mencionado seminario internacional, una cosa es vivir en el sentido de sobrevivir y otra llegar a vivir como humanos, lo cual implica convivencia, intercambios y reciprocidad. Vivir en el sentido de sobrevivir, de no estar muertos, está más en la línea de jakaña, que es el mínimo que nos asemeja a todos los demás seres vivos, sean estos vegetales o animales. Pero, sobre esto, hay que vivir como humanos, con todas esas expresiones de mutua reciprocidad y afecto que ello implica. Esta es también la línea del qamaña, y el hacerlo bien es ya el suma qamaña.

Por lo tanto, el suma qamaña implica un fuerte componente ético, una valoración y aprecio del otro distinto, y una espiritualidad. De allí que lo central del desarrollo para Vivir y Convivir bien ya no es ni puede ser sólo lo económico. Se coloca delante este plus humano. Lo económico y material, es también uno de sus componentes siquiera para superar la mera sobrevivencia. Pero ya no es evidente ni mucho menos que la meta del desarrollo sea crecer más y más en esa línea pase lo que pase con la convivencia entre los humanos y con la Madre Tierra, que es la casa, la "matriz" de todos nosotros.

\section{Más allá del mundo aymara y rural}

Ciertos elementos como los aquí señalados pueden reencontrarse también en las ciudades, dentro de determinados gremios ocupacionales, fraternidades de fiestas, o en determinados barrios; aunque en ese contexto urbano ya no participan todos sino sólo los que tienen más recursos y poder, por lo que se corre mayor riesgo de enfatizar más el lucro, el poder real y el prestigio individual, por encima del servicio, y de perturbar la posibilidad de que todos vayan avanzando más a la par, dentro de la lógica del suma qamaña.

No hay tampoco diferencias muy notables entre comunidades de habla aymara y/o quechua, cuando se encuentran en circunstancias socioeconómicas 
semejantes; pues, en realidad, la lengua no es la que cambia su cultura andina básicamente común. De todos modos, la expresión aymara: suma qamaña permite mayores connotaciones semánticas que su versión quichua/quechua: sumak/sumaq kawsay, ${ }^{3}$ introducida también en la nueva Constitución ecuatoriana. En efecto, desde una perspectiva puramente lingüística, kawsay se asemeja más al jakaña aymara. Algunos quechuistas bolivianos han sugerido que la traducción que mejor captaría los matices de suma qamaña sería allin kawsay o allin tiyakuy.

En otros pueblos indígena originarios también hay concepciones semejantes, aunque se expresen a través de otros conceptos. Si bien los ejemplos podrían multiplicarse en casi todos estos pueblos (tanto en Bolivia como en otros países), me limitaré a esbozar el caso de las comunidades guaraní del Chaco (en las antípodas ecológicas y culturales del mundo andino) por ser el caso más citado en el mencionado artículo 8 de la nueva Constitución boliviana.

Los guaraní hablan sobre todo del ñande reko: "nuestro modo de proceder", en el que juegan también un rol fundamental tanto las relaciones de reciprocidad y el poder compartir la caza, pesca, comida y bebida cuando la hay en abundancia, como la relación de todo ello con el territorio, visto ya no como "Madre Tierra" pero sí como "el lugar y el medio en que se dan las condiciones de posibilidad del modo de ser guarani" (Medina 2002a, 63, interpretando a Melià).

La principal expresión del buen convivir guaraní es seguramente el arete, ${ }^{4}$ su fiesta central, a la que ahora en castellano llaman también Carnaval, y que se celebra sólo en los años con buena producción. Ante todo, se festeja la cosecha del maíz con que preparan sus buenas tinajas de chicha, que todos comparten con alegría hasta que se acaba, mientras bailan en rondas y celebran también el reencuentro con los aña: 'los muertos' (representados por jóvenes adecuadamente ataviados con máscaras) que salen del bosque para unirse a la alegría de todos.

\footnotetext{
${ }^{3}$ En el Ecuador se llama quichua (kichwa] y se pronuncia y escribe sumak, por carecer del contraste entre la consonante palatal $k$ y la futural $q$. El Perú y Bolivia, donde sí existe este contraste, la $q$ arrastra la $i$ hacia la pronunciación fonética [e] (sin ser otro fonema que implique un nuevo sentido), por lo que en castellano la lengua se llama quechua [qhichwa] y el término se pronuncia y escribe sumaq.

${ }^{4}$ Sobre el arete, consultar el trabajo de Nancy Postero en este volumen (página 141).
} 
En términos de utopía, hay que resaltar también el mito (y las migraciones históricas) en busca de la "tierra sin mal" (ivi maräei); es decir, la tierra bella, resplandeciente, húmeda y fértil, en la que todos trabajan, a veces juntos (motirö), y en la que todos comparten los frutos de ese trabajo, así como la gran fiesta con chicha abundante (Melià 1987).

En el Centro de Investigación y Promoción del Campesinado (CIPCA) donde trabajo, tuvimos una experiencia aleccionadora. Nuestro primer objetivo, pensado desde una lógica puramente técnica y política, era apoyar la liberación económica de aquellas comunidades frente a su fuerte dependencia de la agroindustria cruceña a la que los guaraní acudían anualmente varios meses durante la zafra cañera, bajo la coacción de una deuda permanente. Además, con esa ausencia temporal, sus territorios subutilizados resultaban más vulnerables ante el agresivo avance de la agroindustria hacia el sur. Para ello, pensamos que el fuerte sentido comunitario allí, podría enfocarse en nuevas actividades agrícolas y ganaderas que complementaran la auto-subsistencia, abastecida por sus chacos o parcelas familiares, con producción en común más orientada al mercado. Se conformaron así las primeras "comunidades de trabajo", pronto expandidas en bastantes lugares. Sin embargo, llegado el momento de la cosecha de esa parte en común, muchas veces los economistas debieron reformular sus cálculos iniciales de réditos monetarios, porque la primera preocupación de los participantes no era vender el producto, como se había previsto, sino compartir lo más posible con todos los comunarios, sobre todo si se trataba de maíz. Sólo después de quedar todos bien satisfechos, el saldo podía llegar al mercado.

\section{Teorizando más allá}

La persistencia de este enfoque en tantos pueblos, ha llevado a muchos teóricos y hasta filósofos a cuestionar desde ahí las generalizaciones etnocéntricas que suelen hacerse desde el Primer Mundo. Desarrollar todo ello exigiría otras ponencias y libros. Me limitaré, por tanto, a puntear apenas algunas pautas.

Dentro de Bolivia, quien más se ha esforzado para introducir el principio de vivir bien en la cpe y el nuevo Estado ha sido David Choquehuanca, Canciller de Bolivia de 2006 a 2017. El concepto ha sido utilizado de manera casi simultánea en la cpe del Ecuador y ha sido objeto de diversos seminarios a nivel internacional (ver, por ejemplo, alai 2010). 
A un nivel más académico, en Bolivia, quien ha hecho un mayor esfuerzo para sistematizar ideas como las aquí expuestas y enmarcarlas en una reflexión teórica más amplia, ha sido Javier Medina, bien acompañado por Simón Yampara (1991) y otros aymaras. Medina ha explorado también la aplicación práctica de su perspectiva, sobre todo en el nuevo contexto creado a partir de la Ley de Participación Popular (1994) y su planteamiento de reconstrucción y fortalecimiento del nivel municipal, particularmente en las áreas rurales donde el municipio era antes sólo una ficción por su falta de recursos.

Dentro de las numerosas publicaciones de Medina, que apuntan a esa mayor teorización y generalización, aquí llamaré la atención sobre su trilogía publicada con apoyo de la Cooperación Técnica Alemana (GTZ por su sigla en alemán) mediante su proyecto PADEP (Programa Académico de Desarrollo Profesional). Llevan por título: Suma qamaña: La comprensión indígena de la Buena Vida (2001), que enlaza la experiencia aymara con un marco teórico más amplio; Nande reko: La comprensión guaraní de la Vida Buena (2002a), sobre la experiencia guaraní; y La vía municipal hacia la Vida Nueva: Insumos para ajustar la EBRP (2002b), donde recoge y busca insumos para incorporar esos enfoques a la Estrategia Boliviana para la Reducción de la Pobreza. Medina presenta los principios más inclusivos y holísticos de los pueblos indígenas y también de diversos teóricos de todas las latitudes, y los va contrastando con el enfoque mucho más economicista y diseccionador de los modelos dominantes de desarrollo y planificación. Aunque esos textos, a veces, se suben a un lenguaje demasiado abstracto y elitista, son por ahora el sumario más estimulante para comprender las múltiples facetas del suma qamaña a un nivel más general. Me limitaré a enunciar la lista de criterios sugeridos por Medina para acercarnos a la Bolivia "posible y deseable":

\author{
Una sociedad convivial \\ Una sociedad de frugalidad de vida y calidad de vida \\ Una sociedad de alta sinergía \\ Una sociedad de baja entropía \\ Una sociedad del equilibrio \\ Una sociedad eco-simbiótica con su espacio \\ Una sociedad de redes y flujos dinámicos \\ Una sociedad de democracias locales directas
}

No es casual que poco después, en 2003, Medina publicara también, con el mismo apoyo de la GTZ y PADEP, tres gruesos volúmenes con los principales 
aportes de Dominique Temple (2003), el teórico francés que seguramente más ha reflexionado y avanzado al respecto a partir del trabajo pionero de Marcel Mauss (1923) "Ensayo sobre el don", y que-sin duda-mayores lazos ha creado con los pensadores aymaras contemporáneos.

Pero, tampoco es algo tan único. En el fondo, la Declaración de la UNESCO (2001) sobre la diversidad cultural, como fuente principal de nuestro crecimiento en humanidad, y la necesidad de subordinar el desarrollo económico al desarrollo humano y cultural de cada pueblo, se mueve también en esa misma óptica. Lo mismo ocurre con los exitosos esfuerzos de las diversas instancias de las Naciones Unidas por desterrar de una vez aquel falaz promedio de la "renta per cápita" y sustituirlo por el "índice de desarrollo humano".

Las nuevas corrientes sobre desarrollo sostenible, el ecodesarrollo y la protección del medio ambiente van en la misma dirección, de modo que quienes antes despreciaban la típica reverencia y cariño de los pueblos originarios por la Madre Tierra -con la que hay que realizar convites y practicar también la reciprocidad-, ahora se sienten rebasados por estos nuevos enfoques, más cercanos a los de aquellos pueblos "primitivos".

En todo este proceso ocurre una doble revolución copernicana en la concepción del desarrollo. Primera: Ya no gira todo en torno al crecimiento económico, sino que lo económico gira más bien en torno al crecimiento en humanidad. Segunda, tampoco la Madre Tierra -el Cosmos, siendo más inclusivos- gira en torno de los humanos, sino que nosotros también nos sentimos fruto y parte de esta Madre Tierra y Cosmos, y tenemos que avanzar y convivir juntos de una manera armónica. De la prioridad económica se pasa a la humana, y ésta se inserta en lo cósmico, que no excluye lo demás, pero le da un sentido más incluyente. Y sólo entonces podemos comprender qué es realmente el convivir bien e intentar realizarlo.

Mirándolo bien, desde la perspectiva de los grandes ciclos temporales, muchas de esas aparentes innovaciones no hacen más que retornarnos a nuestras fuentes originarias y primigenias. ¿No hay también mucho del suma qamaña, por ejemplo, en el saludo hebraico y bíblico shalom, que significa "paz" en sus diversas acepciones tanto individuales como colectivas e internacionales, y también bien-estar y retorno al equilibrio, a la justicia y la igualdad integral? ¿No encontramos también principios semejantes en muchas otras religiones orientales? 


\section{Sus posibles indicadores}

¿Cómo medir nuestro avance en esa línea del suma qamaña por medio de instrumentos que puedan señalar o "indicar" todo lo anterior? Lo primero que resalta es que -como ya insinuamos más arriba- este "vivir bien" no se puede medir sólo de acuerdo al acceso a determinados bienes materiales cuantificables. No basta tampoco una cuantificación económica, aunque puede ser indispensable incluir ambos aspectos cuando el punto de partida es una situación tal de pobreza que ni siquiera permite sobrevivir.

En este sentido inicial de asegurar la plena sobrevivencia (jakaña), instrumentos internacionales para medir la superación de la pobreza básica, como el Índice de Necesidades Básicas (In)Satisfechas o los Índices de Vulnerabilidad, pueden servir de base para medir esta condición de partida que es sobrevivir; de ahí se puede avanzar hacia vivir bien y finalmente convivir bien.

Amartya Sen nos hizo también un gran avance cuando, con un enfoque más cercano al del vivir bien, logró que en las estadísticas mundiales se arrinconara de una vez por todas, como indicador clave de desarrollo, a la famosa y traicionera "renta per cápita", que consiste en sumar a ricos y pobres para, después, contentarse con sacar y comparar promedios engañosos y perversos. A buena hora, Sen logró sustituirlo por el "Índice de Desarrollo Humano" (IDH), hoy ya generalizado.

Pero quizás se quedó corto en lo de "humano", porque su IDH no llega a entrar en esas características más propiamente "humanas" (humanistas, quizás dirían otros) arriba mencionadas. Sus indicadores sólo se refieren a individuos, prescindiendo de si saben relacionarse o no entre sí y con los demás. Apuntan más al vivir y crecer como individuos que al convivir bien, que es un elemento tan fundamental para crecer en humanidad y para hacerlo en sintonía con la Madre Tierra.

¿Qué otros indicadores necesitamos para abarcar también estas otras dimensiones? Tenemos al menos otras dos vetas: una, que se refiere a la calidad de las relaciones sociales, y otra que se refiere a la calidad de las relaciones con la naturaleza, la Madre Tierra.

En la primera veta podrían incluirse, quizás, algunos de los índices de gobernabilidad desarrollados por el Programa de las Naciones Unidas para el Desarrollo (PNUD), particularmente aquellos que aparecen en el subíndice de Participación y en el de Estabilidad Política. Estos pueden aproximarse en un sentido cercano al concepto de "buen gobierno" (nombre mucho más amigable que ese abstracto anglicismo "gobernanza"). 
En la segunda, también podrían entrar algunos indicadores asociados con el desarrollo sostenible, y otros que ya se están desarrollando en el marco de lo que la cpe 2008 del Ecuador ha llamado sugerentemente los "Derechos de la Naturaleza".

En ambas vetas ya se han hecho intentos de cuantificación, al menos dentro de escalas ordinales. Sin embargo, si entramos en los aspectos más afectivos de la convivencia, es difícil pensar en indicadores universales y transculturales. Seguramente tendrán que diseñarse más bien indicadores o aproximaciones más cualitativas para cada realidad social y cultural.

Como punto de partida, la mejor vía podría ser que, al interior de cada pueblo y cultura, se desarrollen y expliciten los valores más queridos por los pueblos que la viven (como se ha hecho en Bolivia con el suma qamaña); y, a partir de ellos, se podrían explicitar algunas relaciones deseables de convivencia sobre las cuales sea posible averiguar si se cumplen o se violan. Estas relaciones se pueden aplicar, por ejemplo, a la convivencia dentro de la comunidad, a la administración de la justicia o incluso en la celebración conjunta de rituales de producción.

En algún momento habrá que incluir también indicadores de tipo inter-cultural, inter-género, inter-otras categorías que muestren la calidad de la relación, reciprocidad, equidad, convivencia, etc.; entre los que -por una u otra razón- son distintos. Por ejemplo, por su lugar de origen, género, filiación religiosa o política, identidad y hábitos culturales, posición social y económica, etc. La diferencia entre los sujetos y los grupos a que los diversos interlocutores pertenecen es casi siempre parte de toda relación de convivencia; empezando por esa unidad mínima que hace personas (jaqi) a los aymaras, como es la pareja complementaria chachawarmi.

En otro rincón del mundo, el reino de Bután, un pequeño país budista en medio de los Himalayas, tan distante y a la vez tan semejante a la Bolivia andina, encontramos otro ejemplo inspirador. Allí se ha decidido, hace apenas cuatro años, basar su sistema de indicadores en algo comparable a nuestro suma qamaña, pero que allí llaman indicadores de Felicidad Nacional Generalizada (Gross National Happiness o GNH, en inglés). Según Dasho Karma Ura (2009), estos indicadores se distribuyen en las nueve dimensiones siguientes: 


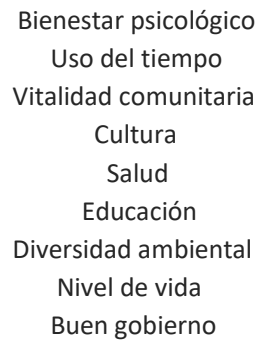

\section{Advertencia final}

Uno de los principales obstáculos para lograr que ese convivir bien llegue a todos -incluyendo los componentes éticos, afectivos y de apertura a los distintos, arriba señalados- es obviamente la estructura dominante de poder, tanto en su dimensión económica como política, la cual coloca a un grupo en el candelero y acapara para sí en menoscabo de los otros. De cara a la acción, la consecuencia, igualmente obvia, es que no es posible lograr el objetivo de convivir bien sin incidir a la vez en esa estructura social, política y económica, para evitar que ocurran las exclusiones. Sólo un cambio estructural en la propia pirámide socio-económica podrá facilitar un cambio igualmente estructural en todo nuestro sistema de convivencia. Este es el hueso más duro de roer.

Ello no quiere decir, sin embargo, que todo se reduce a sólo el factor socio-político ni al económico. Las demás dimensiones, que pasan por la capacidad de vincularnos de manera constructiva con los distintos, tienen también su propia esfera y tareas específicas. Por ejemplo, en algunos regímenes socialistas se logró, aparentemente, achicar las diferencias sociales y económicas. Pero cuando se pretendió reducir y resolver toda la problemática en la esfera de las relaciones de clase, ignorando otras dimensiones, se creó un caldo de cultivo para el conflicto inter-étnico que explotó en muchos escenarios poco después de la caída de esos regímenes socialistas. Por otra parte, sin embargo, será también imposible resolver todos esos otros problemas de convivencia si no se afronta y supera a la vez esa desigualdad en la estructura general de poder. 


\section{BIBLIOGRAFIA CITADA}

ALAI (Agencia Latinoamericana de Información) 2010. América Latina en Movimiento № 452. Sumak kawsay: recuperar el sentido de la vida. Quito, Artes Gráficas SILVA. [https://www.alainet.org/sites/default/files/alai452w.pdf] página descargada el 15 de diciembre, 2019.

BERTONIO, Ludovico. 1984 [1612]. Vocabulario de la lengua aymara. Edición facsimilar con Introducción de Xavier Albó y Félix Layme. Cochabamba: CERES, IFEA y MUSEF.

CONSTITUCIÓN POLÍTICA DEL ESTADO. 2009. La Paz. [https://sea.gob.bo/digesto/CompendioNormativo/01.pdf] página descargada el 15 de diciembre, 2019.

DE LUCA, M. 1987. Diccionario práctico aymara-castellano, castellanoaymara. La Paz / Cochabamba: Los Amigos del Libro.

FARAH H. Ivonne y Luciano Vasapollo, coords. 2011. Vivir Bien: ¿'Paradigma no capitalista? La Paz: CIDES-UMSA.

KARMA URA, Dasho. 2009. Gross National Happiness. Centre for Butan Studies \& GNH. [https://www.grossnationalhappiness.com/] página descargada el 15 de diciembre, 2019.

LAYME P., Félix. 2004. Diccionario bilingüe: aymara castellano, castellanoaymara. La Paz: Consejo Educativo Aymara.

LIRA, Jorge. 1982 [1941]. Diccionario Kkechuwa-español. 2ª edición autorizada por el autor. Bogotá: Secretaría Permanente del Convenio "Andrés Bello". Instituto Internacional de Integración, Instituto Andino de Artes Populares.

MAUSS, Marcel. 1923. "Essai sur le don. Forme et raison de l'échange dans les societés archaïques". L'Année Sociologique 1. 30-186.

[https://babel.hathitrust.org/cgi/pt?id=uc1.31210007521766\&view=1 up\&seq=11] página descargada el 15 de diciembre, 2019.

MEDINA, Javier. 2001. Suma qamaña: La comprensión indígena de la buena vida. La Paz: GTZ, Proyecto de Apoyo a la Planificación y Gestión Participativa Municipal. [https://filosofiadelbuenvivir.com/wpcontent/uploads/2014/08/Suma-Qama\%C3\%B1a-la-Vida-Buena.Bolivia-GTZ-2008.pdf] página descargada el 15 de diciembre, 2019.

---. 2002a. Ñande Reko: La comprensión guaraní de la Vida Buena. La Paz: PADEP/Componente Qamaña. [http://filosofiadelbuenvivir.com/wpcontent/uploads/2014/08/comprension_guarani-\%C3\%91ANDEREKO.pdf] página descargada el 15 de diciembre, 2019.

---. 2002b. La vía municipal hacia la Vida Buena: Insumos para ajustar la EBRP. La Paz: GTZ, PADEP. [https://www.bivica.org/files/viamunicipal.pdf] página descargada el 15 de diciembre, 2019.

MELIÀ, Bartomeu. 1987. “La tierra sin mal de los guaraní. Economía y Profecía”. Asunción: Suplemento Antropológico 22(2): 81-97.

TEMPLE, Dominique. 2003. Teoría de la reciprocidad. 3 tomos. Juan Cristóbal MacLean, Rosa María Montes, Deniele Marie Marret, Jacqueline Michaux, Pedro Portugal, Javier Medina, trads. La Paz: PADEP, GTZ. 
YAMPARA, Simón, ed. 1991. Naciones autóctona originarias: vivir-convivir en tolerancia y diferencia. 3er. Seminario Amáutico del Área Andina Pre y Post V Centenario. La Paz: Editorial Qamañ-pacha, CADA (Centro Andino de Desarrollo Agropecuario).

\section{ULIS D-Serle This journal is published by the University Library System of the University of Pittsburgh as part of its D-Scribe Digital Publishing Program, and is cosponsored by the University of Pittsburgh Press.}

